\title{
REVIEW
}

\section{Berger in retrospect: effect of varied weight training programmes on strength}

\section{R N Carpinelli}

Br J Sports Med 2002;36:3-324

The evidence that multiple sets of exercise are superior to a single set for maximal strength gains, as suggested by Berger in 1962, is reviewed. The validity and practical significance of Berger's strength training study are questioned. Well controlled, methodologically sound studies that minimise confounding variables are required to support the hypothesis that multiple sets of exercise elicit superior gains in strength.

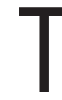
here is a pervasive misconception that multiple sets of a strength training exercise are superior to a single set for increasing muscular size and strength. The prevalent recommendation, which appears in exercise physiology textbooks and strength training reviews, is to perform multiple sets (at least three) of each exercise. However, there is very little evidence to support the preponderant belief that multiple sets are superior to a single set. Fig 1 illustrates the labyrinth of cross referencing by physiologists who recommend the execution of multiple sets. The only evidence cited to support their multiple set training philosophy is one strength training study by Berger, ${ }^{1}$ which is perhaps the genesis of the unsubstantiated belief that multiple sets are required for optimal gains in strength. Therefore, a close examination of this study is warranted. This retrospective is based on the original information published in Berger's study, ${ }^{1}$ as well as personal written and telephone correspondence (1998) with Dr Berger in which he clarified specific methodologies that were not elucidated in the original publication. He expressed his opinion-both before his research and currently-that multiple sets are required for maximal increases in muscular strength and hypertrophy (personal communication; 1998).

\section{BERGER (1962)}

Berger ${ }^{1}$ reported that nine groups of college age

Correspondence to: Dr Carpinelli, Human Performance Laboratory, Department of Health, Physical Education and Human Performance Science, Woodruff Hall, Adelphi University, Garden City, New York 11530

USA; q-nautilus@ worldnet.att.net

Accepted

18 February 2002 men (about 20 in each group) performed strength training exercises three times a week for 12 weeks. The students $(n=177)$ were enrolled in one of nine weight training classes and not equated or randomised before training. There was no control group. In addition to their regular weight training programme, which is not described in the report, ${ }^{1}$ participants performed different combinations of sets and repetitions in the free weight bench press exercise-for example, three sets of six repetitions (III-6). Berger ${ }^{1}$ used roman and arabic numerals to represent sets and repetitions respectively. All nine groups showed a significant increase $(p<0.05)$ in one repetition maximum (1RM) bench press (table 1 ).

Berger's ${ }^{1}$ Table 4 ( $p$ 176) had three previously unchallenged typographical errors. The errors have been corrected (row 6, column 5 changed from III-2 to I-6; row 2, column 9 changed from III-6 to Groups; and row 3, column 9 changed from Groups to III-6), and the results for the end of 12 weeks of training are presented here in table 2 (personal communication; 1998). Berger ${ }^{1}$ notes that groups differing at the 0.05 level are separated by dashes. Table 2 shows which of Berger's ${ }^{1}$ nine groups (36 comparisons) differ significantly and those that do not. After 12 weeks of training, group III-6 is separated by dashes from II-6, but not from I-6. Similarly, group III-2 is separated by dashes from II-2 but not from I-2. That is, the increase in IRM bench press for the III-6 group was significantly greater $(\mathrm{p}<0.05)$ than for the II-6 group, but not significantly greater than for the I- 6 group. The II- 6 group is not separated by dashes from the I- 6 group. Likewise, the increase in strength for group III- 2 was significantly greater $(p<0.05)$ than for the II-2 group but not significantly greater than for the I-2 group. The II-2 group is not separated by dashes from the I-2 group. If a greater number of sets were really better than fewer sets, three sets would be better than one set, as well as better than two sets-they were not. There was no significant difference in IRM between groups I-10 and II-10, groups I-10 and III-10, or groups II-10 and III-10. Table 3 shows that seven out of nine of Berger's ${ }^{1}$ comparisons between groups who performed the same number of repetitions $(2,6$, or 10$)$ showed no significant difference in the magnitude of strength gains as a result of performing single or multiple sets. Whenever multiple comparison testing is used, the chance of making a type I error is increased-that is, rejecting the null hypothesis when the null hypothesis is actually true. Perhaps the differences that Berger ${ }^{1}$ reported were due to chance or random error (personal communication; 1998).

Berger $^{1}$ also compared the results of training with one, two, or three sets by combining the nine groups according to the number of sets performed. Training with either one set or two sets produced similar improvements in strength ( $22.3 \%$ and $22.0 \%$ respectively), whereas training with three sets elicited an increase of $25.5 \%$. The difference $(3.2 \%)$ between training with one set and three sets was significant $(\mathrm{p}<0.05)$ after 12 weeks of training. If it is assumed that the difference was not caused by random error, the practical significance of a $1.8 \mathrm{~kg}$ difference as a result of performing three sets compared with one set 


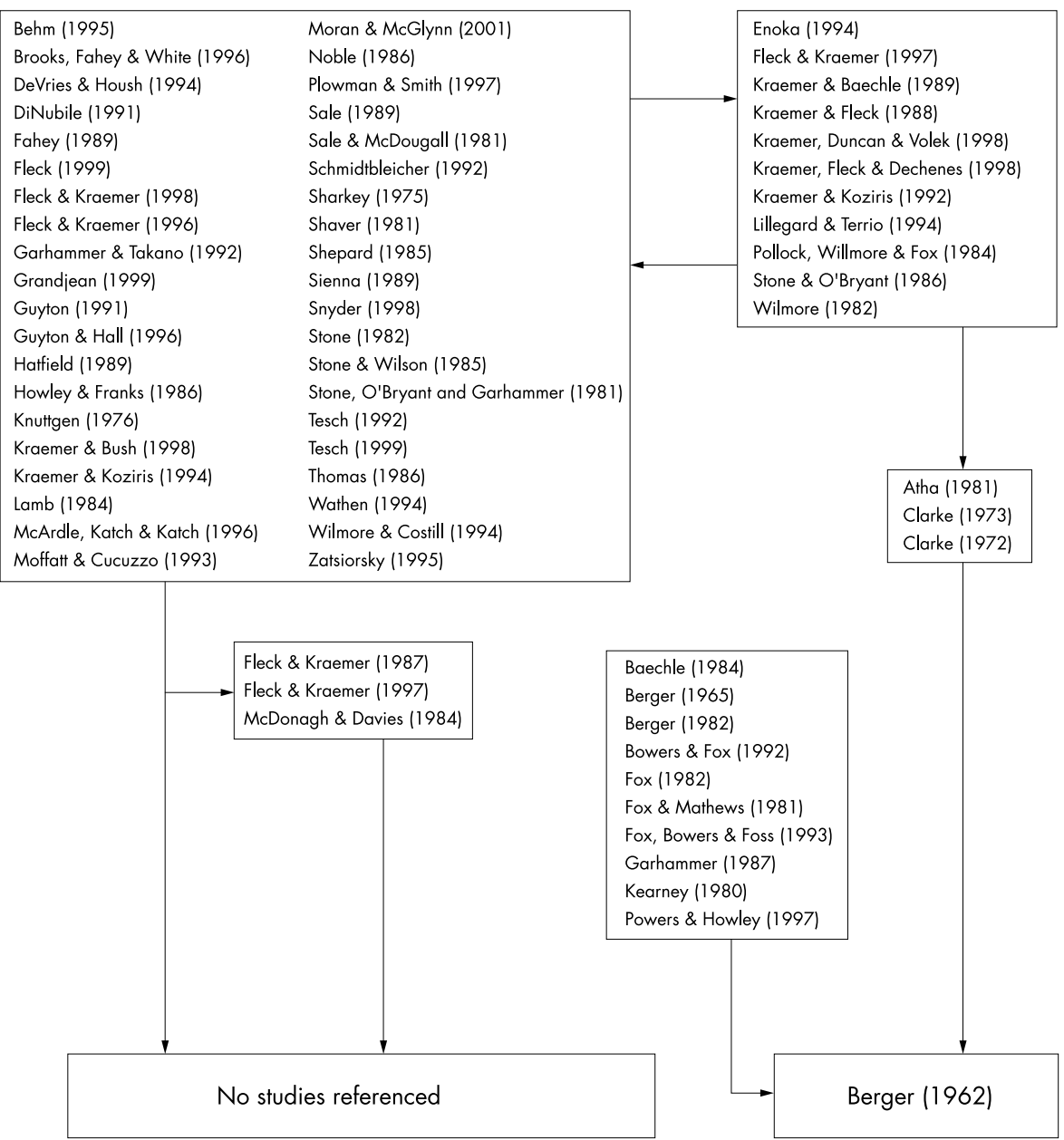

(from Figure 2 of Berger's study ${ }^{1}$ ) is questionable (personal communication; 1998). That is, for most of the strength training population and with the exception of elite strength athletes, a 3\% difference in strength may not be worth $300 \%$ greater time and energy expenditure.

Berger ${ }^{1}$ reported that the greatest difference in the rate of improvement between the combined one set, two set, and three set groups occurred during the second three weeks (weeks 4-6) of training. During this period the increase was $5.0 \%, 5.7 \%$, and $7.8 \%$, for the one, two, and three set groups respectively. Perhaps there was a greater learning effect for the combined three set groups in the early phase of the study. A movement such as the free weight bench press exercise, which requires a high level of strength, is considered a skilled act, and control of the involved muscles by the nervous system is

Table 1 Significant increase $(p<0.05)$ in one repetition maximum (1RM) bench press for all nine groups after 12 weeks of training

\begin{tabular}{lrl}
\hline Group (n) & $\uparrow \mathrm{kg}$ & $\% \uparrow$ \\
\hline I-2 (19) & 11.3 & 20.0 \\
II-2 (18) & 9.3 & 17.3 \\
III-2 (18) & 13.3 & 23.5 \\
I-6 (22) & 14.5 & 25.5 \\
II-6 (20) & 12.9 & 22.9 \\
III-6 (21) & 16.7 & 29.6 \\
I-10 (19) & 12.2 & 21.6 \\
II-10 (21) & 14.2 & 25.1 \\
III-10 (19) & 13.0 & 23.0 \\
\hline Data from Berger. ${ }^{\prime}$ & & \\
\end{tabular}

very complex. Therefore, when an unfamiliar exercise is introduced, the increase in strength is largely because of adaptations in the nervous system that optimise control of the muscles involved in the exercise and the coordination necessary to perform the exercise efficiently. These neural adaptations are predominant in the first few weeks of training. ${ }^{2}$ For the rest of the 12 week study (weeks 7-12), the difference between groups gradually diminished until the rate of improvement was practically the same during the last three weeks of training. In fact, the rate of improvement for weeks 9-12 was $4.0 \%, 3.2 \%$, and $3.3 \%$ for the one, two, and three set groups respectively. Similarly, for the specific number of repetitions (six) that Berger ${ }^{1}$ claimed to be optimal, the rate of strength increase for the last three weeks was $4.8 \%, 3.0 \%$, and $4.0 \%$ for group I-6, II- 6 , and III-6 respectively.

Table 2 Bench press one repetition maximum (1RM) for the nine groups after 12 weeks of training

\begin{tabular}{lllll}
\hline Groups & Mean $(\mathrm{kg})$ & \multicolumn{3}{l}{ Significant difference } \\
\hline III-6 & 73.3 & III-6 & & \\
I-6 & 71.0 & [I] & I-6 & II-10 \\
II-10 & 70.8 & [I] & {$[I]$} & III-2 \\
III-2 & 69.9 & III-2 & {$[I]$} & III-10 \\
III-10 & 69.6 & III-10 & {$[I]$} & II-6 \\
II-6 & 69.5 & II-6 & {$[I]$} & {$[I]$} \\
I-10 & 68.8 & I-10 & {$[I]$} & II] \\
I-2 & 67.9 & I-2 & I-2 & II-2 \\
II-2 & 66.4 & II-2 & II-2 & .
\end{tabular}

Data from Berger.' "Groups differing at the 0.05 level are separated by dashes" (Berger', p176). 
Table 3 Comparison of groups performing a similar number of repetitions $(2,6$, or 10$)$ after 12 weeks

\begin{tabular}{ll}
\hline Groups & \\
\hline III-6 and II-6 & SD \\
III-6 and I-6 & NSD \\
II-6 and I-6 & NSD \\
III-2 and II-2 & SD \\
III-2 and I-2 & NSD \\
II-2 and I-2 & NSD \\
III-10 and II-10 & NSD \\
III-10 and I-10 & NSD \\
II-10 and I-10 & NSD \\
\hline
\end{tabular}

Data from Berger.'

$S D$, Statistically significant difference $(p<0.05)$ between groups in one repetition maximum (IRM) bench press; NSD, no statistically significant difference between groups.

In the Results section, Berger ${ }^{1}$ claims that more sets, more repetitions per set, and more total repetitions at each training session resulted in a greater improvement in strength. His implication is that three sets of ten repetitions (III-10)- the greatest volume of exercise-is the most effective. However, contrary to Berger's ${ }^{1}$ claim, table 2 shows that there was a significantly $(\mathrm{p}<0.05)$ greater increase in strength for subjects in the III-6 group (29.6\%), who performed 18 repetitions per session, compared with subjects in the III-10 group (23.0\%), who performed 30 repetitions per session.

Berger $^{1}$ used an analysis of covariance to test for any significant interaction between sets and repetitions-that is, whether one, two, or three sets might be better systematically in combination with two, six, or ten repetitions. The $F$ ratio for interaction was not significant at any period of training $(3,6$, 9, or 12 weeks). In Conclusion 6, Berger ${ }^{1}$ contends that training with one, two, or three sets in discrete combination with two, six, or ten repetitions (interaction) was not systematically more effective in improving strength than other combinations. However, in Conclusion 7, he declares that a combination of six repetitions and three sets was more effective in improving strength than any other combination of sets and repetitions. ${ }^{1}$ Berger ${ }^{1}$ reports no significant interaction, and then antithetically claims that the combination of three sets and six repetitions is more effective than any other combination of sets and repetitions.

Berger's ${ }^{1}$ subjects were enrolled in weight training classes. They all performed and were graded on other exercises besides the bench press (personal communication; 1998). However, Berger $^{1}$ reported only the results of the bench press exercise. He did not control the number of sets and repetitions performed for the other weight training exercises (personal communication; 1998), and those exercises involving the triceps, pectorals, and deltoids may have confounded the results of the IRM bench press. Participants chose their own rest time between sets and exercises (personal communication; 1998). Although the optimal rest time between sets or exercises is unknown, similar rest between sets would have eliminated recovery time as a confounding variable. Berger ${ }^{1}$ did not control for the speed of movement, which was self selected by each participant (personal communication; 1998). Different speeds of movement within and among the nine groups may have affected his results.

Participants were given enough assistance to accomplish a specific number of repetitions $(2,6$, or 10$)$. The amount of assistance, the specific spotter for each participant, the number of assisted repetitions, and how often the assisted repetitions were applied in each group for each participant were neither controlled nor documented (personal communication; 1998). When a subject thought that he could perform more than the designated number of repetitions, he terminated the set at the designated number and increased the weight at the next session (personal communication; 1998)that is, participants did not exceed the designated number of repetitions $(2,6$, or 10$)$. Completing every set to muscular fatigue would have ensured similar maximal exercise intensity (effort) for everyone. Because the sets were terminated at a specific number of repetitions, there was no control for exercise intensity (degree of effort or fatigue) within or among the groups. The concept of muscular fatigue is highly subjective and not universally defined or fully understood. As fatigue begins to develop within the muscle as a result of several submaximal muscle actions, more motor units are recruited and motor unit firing rates increase in an attempt to maintain the desired force output. When the force generating capacity drops below the required force, despite full recruitment and optimal firing rates of motor units, it is generally defined as muscular fatigue. ${ }^{3}$ The causes may range from motivation to maintain voluntary effort to failure in the contractile mechanism. The various processes that cause fatigue during high intensity strength training may provide the stimulus for increased strength. ${ }^{4}$ It is speculated that the degree of motor unit activation determines the magnitude of the strength training response and that intensity is the most contributing factor for increasing strength. ${ }^{46}$

\section{BERGER (1963)}

If three sets of six repetitions $(3 \times 6)$ were superior to other training protocols, subsequent studies would have replicated those results. However, a follow up study by Berger ${ }^{7}$ failed to support his conclusion that $3 \times 6$ is the best training protocol. He trained three groups of young men three times a week for nine weeks performing a $3 \times 6(n=14), 3 \times 10(n=19)$, or 6 $\times 2(n=15)$ protocol in the free weight bench press exercise. All groups showed a significant $(\mathrm{p}<0.001)$ increase in IRM bench press $(21.3 \%, 20.0 \%$, and $16.9 \%$ respectively), with no significant difference among the groups. That is, the $3 \times 6$ protocol was not superior to the $3 \times 10$ protocol. In Berger's previous investigation, ${ }^{1}$ he reported that the $3 \times 6$ protocol showed a significantly greater increase in IRM bench press than the 3 $\times 10$ protocol. Berger ${ }^{7}$ concluded that further research was required to determine the optimum combination of sets and repetitions for the greatest improvement of strength. In a summary of his strength training research, Berger ${ }^{8}$ recommends executing at least three sets at each session. He cites his 1962 study $^{1}$ in support of his high volume training philosophy.

\section{BERGER (1972)}

Berger ${ }^{9}$ trained three groups of young men three times a week for eight weeks. They performed one $(n=57)$, two $(n=20)$, or three sets $(n=20)$ of static bench press exercise by attempting to raise an immovable bar with a maximum effort for $6-8$ seconds at two positions (with the bar on the chest and at $90^{\circ}$ elbow flexion). There was a significant $(\mathrm{p}<0.01)$ increase in dynamic 1RM bench press strength for the one, two, and three set groups $(19.8 \%, 15.4 \%$, and $21.7 \%$ respectively), with no significant difference among the groups. Berger ${ }^{9}$ concluded that training with one, two, or three sets produces approximately the same improvement in dynamic strength. However, he subsequently recommended performing at least three to five sets, ${ }^{10}$ substantiated only by his 1962 study.

\section{DISCUSSION}

"There is very little peer reviewed evidence to support a high volume strength training protocol."

In his book Conditioning for men, Berger ${ }^{11}$ recommends performing three to five sets of each exercise for optimal strength, and in his Introduction to weight training, ${ }^{12}$ he 
Table 4 Studies reporting no significant difference in strength gains as a result of performing a greater number of sets

\begin{tabular}{ll}
\hline Number of sets & Reference number \\
\hline 1 and 2 & $14-35$ \\
1 and 3 & $36-55$ \\
1,2 , and 3 & $9,56-58$ \\
1,2 , and 4 & 59 \\
2 and 3 & 60 \\
2,3 , and 4 & 61 \\
3 and 6 & 7,62 \\
3,4, and 5 & 63 \\
3,5 , and 7 & 64 \\
3,6 , and 8 & 65 \\
$5-6$ and $8-9$ & 66 \\
5 and 10 & 67 \\
5 and 15 & 68 \\
\hline
\end{tabular}

recommends performing five to nine sets of each exercise. In his textbook Applied exercise physiology, ${ }^{13}$ Berger claims that three sets are more effective than fewer sets for maximising strength. The only reference that Berger cites in the aforementioned books ${ }^{11}{ }^{13}$ is his 1962 strength training study. ${ }^{1}$ Berger still believes that a great volume of exercise is required for optimal strength gains (personal communication; 1998). However, there is very little peer reviewed evidence to support a high volume strength training protocol. Despite the numerous confounding variables that obfuscate Berger's ${ }^{1}$ results, dozens of physiologists continue to cite his study in an attempt to support their unsubstantiated multiple set strength training doctrine.

If the multiple set training philosophy-the volume theory-were a valid training concept, the results of Berger's ${ }^{1}$ study would have been replicated in most of the subsequent research-and they have not. There are 57 studies, $^{79}{ }^{14-68}$ albeit many with potentially confounding variables, that show no statistically significant difference in the magnitude of strength gains or muscular hypertrophy (whenever measured) as a result of performing a greater number of sets (table 4 ). The studies in table 4 involved trained and untrained men and women of various ages, performing a variety of exercises for different muscle groups, with machines and free weights, for durations up to six months. The primary purpose in 17 of the studies $^{16} 18252734$ was to evaluate particular health benefits of strength training and not specifically investigate the effect of single versus multiple sets on strength. Although statistical comparisons of the average strength gains were not reported, the results of performing two sets for each of three lower body exercises and one set for each of eight upper body exercises were almost identical in these studies $(38.2 \%$ and $42.6 \%$ respectively). The results are consistent with a threshold theory, ${ }^{6}$ rather than a volume theory. That is, it appears that for adaptations to occur, such as increased muscular strength and hypertrophy, the stimulus needs to be applied only once each session.

Two criticisms of many strength training studies-inherent in Berger's ${ }^{1}$ study as well (personal communication; 1998) are that they are poorly controlled or recruited untrained participants, or both. However, some recent studies have appropriately addressed these criticisms. For example, in a very well controlled study, Starkey et $a l^{51}$ randomly assigned healthy untrained men and women (18-50 years of age) to a one set $(n=18)$, three set $(n=20)$, or control $(n=10)$ group. Both training groups performed $8-12$ repetitions to volitional fatigue using a two second concentric and four second eccentric protocol for dynamic bilateral knee extension and knee flexion exercises on two MedX strength machines three times a week for 14 weeks. They did not participate in any other form of training for the duration of the study. The three set group rested for one to three minutes between sets. Resistance was increased about $5 \%$ at the subsequent session when 12 or more repetitions were completed in good form. All sessions were monitored by the investigators, and the amount of resistance, number of repetitions, and rating of perceived exertion were recorded after each set. Peak knee extension torque at seven angles significantly increased $(\mathrm{p}<0.05)$ in both the one set $(18-36 \%)$ and three set $(13-27 \%)$ groups. Peak knee flexion torque at the same angles increased $(\mathrm{p}<0.05)$ in both the one set $(13-35 \%)$ and three set $(8-41 \%)$ groups. There was no significant difference between the one set and three set groups in either knee extension or knee flexion peak torque. Both groups had similar significant increases $(\mathrm{p}<0.01)$ in dynamic training resistance for both exercises. Ultrasound scans showed a significant increase $(p<0.01)$ in muscle thickness, with no significant difference between the one set and three set groups.

Hass et $a l^{41}$ randomly assigned 42 male and female recreational weightlifters (20-50 years of age), with an average of 6.2 years of strength training experience, to one of two training groups: one set $(n=21)$ or three set $(n=21)$. All participants were previously using the one set protocol (one circuit of nine exercises) three times a week. The one set group continued to perform one set of each exercise and the three set group performed three sets of each exercise on the nine MedX machines three times a week for 13 weeks. They executed each set of 8-12 repetitions using a two second concentric and four second eccentric protocol to volitional fatigue. Subjects rested one minute between exercises and three to five minutes between circuits. The investigators monitored each training session and recorded the resistance, number of repetitions, and rating of perceived exertion after each exercise. When 12 or more repetitions were completed in strict form, the resistance was increased $5-10 \%$ at the next session. Dynamic muscular strength was assessed using the IRM on five of the nine MedX machines, as well as maximal isometric knee extension and knee flexion strength on a MedX ergometer. Seven skinfolds and six circumferences were assessed to estimate body composition. After 13 weeks, both groups showed a significant increase $(\mathrm{p}<0.05)$ in dynamic 1RM strength $(8-14 \%)$ on the five exercises, with no significant difference in the magnitude of strength between the one set and three set groups. Both groups significantly increased $(p<0.05)$ maximal isometric knee extension and knee flexion torque, with no significant difference between groups. Lean body mass significantly increased $(\mathrm{p}<0.05)$ in both groups, with no significant difference between groups. There were originally 49 subjects in this strength training study, ${ }^{41}$ but five had to be removed by the investigators because of poor compliance, and two other participants withdrew because of injuries. All seven subjects who did not complete the study were from the three set group. The greater volume of exercise (multiple sets) in the three set group may have contributed to their lower compliance.

\section{CONCLUSION}

One consequence of accepting an unsubstantiated training philosophy is that many researchers have assumed for decades that a minimum of three sets of each exercise is required to produce adaptations or acute responses to resistance exercise. For example, as a result of different strength training programmes, adaptations have recently been reported for women, ${ }^{69}{ }^{70}$ men, ${ }^{71-75}$ and both sexes, ${ }^{7677}$ as well as acute responses in women, ${ }^{78}$ men, ${ }^{79}$ and both sexes. ${ }^{80}$ None of the researchers attempted to justify their exercise protocols, which comprised at least three sets of each exercise. Perhaps the greater ramification is that many dedicated trainees spend excessive time and perform an unnecessary volume of exercise (three to five sets compared with one set). 


\section{Take home message}

The genesis of the belief that multiple sets of each exercise are superior to a single set for maximal strength gains is one very poorly controlled 40 year old strength training study by Berger. The evidence to support the performance of multiple sets is extremely weak. Most of the evidence suggests that single and multiple sets produce similar increases in strength.

"More research is required to determine if the potential health benefits from strength training require multiple set protocols."

More research is required to determine if the potential health benefits from strength training require multiple set protocols. However, Kelley and Kelley ${ }^{81}$ in a meta-anaylsis of randomised controlled trials reported that various strength training protocols, such as the number of sets, did not influence the significant decrease in resting systolic and diastolic blood pressure in adults.

Replication of Berger's ${ }^{1}$ results, using greater controls and randomisation, and a corroboration of evidence from different researchers is necessary to support the practical significance of performing multiple sets of each exercise. If the experimental treatment-for example, the number of sets-had a really strong effect on the outcome-for example, muscular strength or hypertrophy-it would influence the outcome whenever the experiment, or a similar investigation, is repeated. It should be recognised that no well controlled study has shown single set training to be superior to multiple set training - that is, there appears to be no detrimental effect from performing multiple sets. The benefit of single set training is time efficiency because most of the time it elicits similar strength gains in less time. Only five studies ${ }^{12} 85$ report a significantly greater increase in strength as a result of multiple sets. The preponderance of research reports no difference in the magnitude of strength gains or muscular hypertrophy as a result of performing a greater number of sets.

\section{REFERENCES}

1 Berger RA. Effect of varied weight training programs on strength. Res $Q$ 1962;33:168-81.

2 Sale DG. Neural adaptation to strength training. In: Komi PV, ed. Strength and power in sport. Oxford: Blackwell Scientific Publications, 1992:249-65.

3 Sale DG. Influence of exercise and training on motor unit activation. Exerc Sport Sci Rev 1987; 15:95-151.

4 Rooney KJ, Herbert RD, Balnave RJ. Fatigue contributes to the strength training stimulus. Med Sci Sports Exerc 1994;26:1160-4.

5 Feigenbaum MS, Pollock ML. Prescription of resistance training for health and disease. Med Sci Sports Exerc 1999;31:38-45.

6 Winett RA, Carpinelli RN. Examining the validity of exercise guidelines for the prevention of morbidity and all-cause mortality. Ann Behav Med 2000;22:237-45.

7 Berger RA. Comparative effects of three weight training programs. Res Q 1963;34:396-8

8 Berger RA. Application of research findings in progressive resistance exercise to physical therapy. Journal of the Association of Physical and Mental Rehabilitation 1965;19:200-3.

9 Berger RA. Effect of varied sets of static training on dynamic strength. American Corrective Therapy Journal 1972;26:52-4.

10 Berger RA. Strength improvement. Strength and Health 1972 Aug:44-5, 70-1.

11 Berger RA. Conditioning for men. Boston: Allyn and Bacon, 1973.

12 Berger RA. Introduction to weight training. Englewood Cliffs, NJ: Prentice-Hall, 1984.

13 Berger RA. Applied exercise physiology. Philadelphia: Lea \& Febiger, 1982.

14 Capen EK. Study of four programs of heavy resistance exercise for development of muscular strength. Res Q 1956;27:132-42.

15 Coleman AE. Nautilus vs Universal Gym strength training in adult males. American Corrective Therapy Journal 1977;31:103-7.

16 Girouard CK, Hurley BF. Does strength training inhibit gains in range of motion from flexibility training in older adults? Med Sci Sports Exerc 1995;27:1444-9.
17 Graves JE, Holmes BL, Leggett SH, et al. Single versus multiple se dynamic and isometric lumbar extension training. In: Eleventh International Congress of the World Confederation for Physical Therapy. Proceedings Book III. 1991:1340-2.

18 Hurley BF, Redmond RA, Pratley RE, et al. Effects of strength training on muscle hypertrophy and muscle cell distribution in older men. Int J Sports Med 1995;16:378-84.

19 Koffler KH, Menkes A, Redmond RA, et al. Strength training accelerates gastrointestinal transit in middle-aged and older men. Med Sci Sports Exerc 1992;24:415-19.

20 Lemmer JT, lvey FM, Ryan AS, et al. Effect of strength training on resting metabolic rate and physical activity: age and gender comparisons. Med Sci Sports Exerc 2001;33:532-41

21 Martel GF, Horblut DE, Lott ME, et al. Strength training normalizes resting blood pressure in 65- to 73-year-old men and women with high normal blood pressure. J Am Geriatr Soc 1999;47:1215-21.

22 Menkes A, Mazel S, Redmond RA, et al. Strength training increases regional bone mineral density and bone remodeling in middle-aged and older men. J Appl Physiol 1993;74:2478-84.

23 Miller JP, Pratley RE, Goldberg AP, et al. Strength training increases insulin action in healthy 50- to 65-yr-old men. J Appl Physiol 1994;77: 1122-7.

24 Nicklas B J, Ryan AJ, Treuth MM, et al. Testosterone, growth hormone and IGF-I responses to acute and chronic resistive exercise in men aged 55-70 years. Int J Sports Med 1995; 16:445-50.

25 Parker ND, Hunter GR, Treuth MS, et al. Effects of strength training on cardiovascular responses during a submaximal walk and a weight-loaded walking test in older females. J Cardiopulm Rehabil 1996 16:56-62.

26 Pollock MH, Graves JE, Bamman MM, et al. Frequency and volume of resistance training: effect on cervical extension strength. Arch Phys Med Rehabil 1993:74:1080-6.

27 Pratley R, Nicklas B, Rubin $M$, et al. Strength training increases resting metabolic rate and norepinephrine levels in healthy $50-65-y r$ old men. $J$ Appl Physiol 1994;76:133-7.

28 Rhea PL, Ryan AS, Nicklas B, et al. Effects of strength training with and without weight loss on lipoprotein-lipid levels in postmenopausal women. Clinical Exercise Physiology 1999;1:138-44.

29 Rubin MA, Miller JP, Ryan AS, et al. Acute and chronic resistive exercise increase urinary chromium excretion in men as measured with an enriched chromium stable isotope. J Nutr 1998;128:73-8.

30 Ryan AS, Treuth MS, Rubin MA, et al. Effects of strength training on bone mineral density: Hormonal and bone turnover relationships. J Appl Physiol 1994;77:1678-84

31 Ryan AS, Pratley RE, Elahi D, et al. Resistive training increases fat-free mass and maintains RMR despite weight loss in postmenopausal women. J Appl Physiol 1995;79:818-23.

32 Ryan AS, Pratley RE, Elahi D, et al. Changes in plasma leptin and insulin action with resistive training in post-menopausal women. Int J Obes 2000;24:27-32

33 Ryan AS, Hurlbut DE, Lott ME, et al. Insulin action after resistive training in insulin resistant older men and women. J Am Geriatr Soc 2001;49:247-53.

34 Treuth MS, Ryan AS, Pratley RE, et al. Effects of strength training on total and regional body composition in older men. J Appl Physio 1994:77:614-20.

35 Westcott WL. 4 key factors in building a strength program. Scholastic Coach 1986;55:104-5, 123.

36 Bemben DA, Fetters NL Bemben MG, et al. Musculoskeletal responses to high- and low-intensity resistance training in early postmenopausal women. Med Sci Sports Exerc 2000;32:1949-57.

37 Curto MA, Fisher MM. The effect of single vs. multiple sets of resistance exercise on strength in trained males. Med Sci Sports Exerc 1999;31 (suppl):S114.

38 De Hoyos DV, Herring D, Garzarella L, et al. Effect of strength training volume on the development of strength and power in adolescent tennis players. Med Sci Sports Exerc 1997;29(suppl):S164.

39 De Hoyos DV, Abe T, Garzarella L, et al. Effects of 6 months of high- or low-volume resistance training on muscular strength and endurance. Med Sci Sports Exerc 1998;30(suppl):S165.

40 Fincher GE. The effect of high intensity resistance training on peak upper and lower body power among collegiate football players. Med Sci Sports Exerc 2000;32(suppl):S152.

41 Hass CJ, Garzarella L, De Hoyos D, et al. Single versus multiple sets in ong-term recreational weightlifters. Med Sci Sports Exerc 2000;32:235-42.

42 Jacobson BH. A comparison of two progressive weight training techniques on knee extensor strength. Athletic Training 1986;21:315-18, 390.

43 Kosmahl EM, Mackarey PJ, Buntz SE. Nautilus training system versus traditional weight training system. J Orthop Sports Phys Ther $1989 ; 11: 253-8$

44 Larshus JL, Hoeger WWK, Moore JR. Effects of multiple exercise training on the development of tricep strength. Res Q Exerc Sport 1997 Mar(suppl):A33-4.

45 Leighton JR, Holmes D, Benson J, et al. A study of the effectiveness of ten different methods of progressive resistance exercise on the development of strength, flexibility, girth and bodyweight.Journal of the Association of Physical and Mental Rehabilitation 1967;21:78-81.

46 Messier SP, Dill ME. Alterations in strength and maximal oxygen uptake consequent to Nautilus circuit weight training. Res Q Exerc Sport $1985 ; 56: 345-51$ 
47 Pollock ML, Abe T, DeHoyos DV, et al. Muscular hypertrophy responses to 6 months of high- or low-volume resistance training. Med Sci Sports Exerc 1998;30(suppl):S1 16

48 Reid CM, Yeater RA, Ullrich IH. Weight training and strength, cardiorespiratory functioning and body composition. Br J Sports Med 1987; $21: 40-4$

49 Sanborn K, Boros R, Hruby J, et al. Short-term performance effects of weight training with multiple sets not to failure vs. a single set to failure in women. J Strength Cond Res 2000;14:328-31.

50 Silvester LJ, Stiggins C, McGown C, et al. The effect of variable resistance and free-weight training programs on strength and vertical jump. National Strength and Conditioning Association Journal 1982;3:30-3.

51 Starkey DB, Pollock ML, Ishida Y, et al. Effect of resistance training volume on strength and muscle thickness. Med Sci Sports Exerc 1996;28:1311-20.

52 Stowers T, McMillan J, Scala D, et al. The short-term effects of three different strength-power training methods. National Strength and Conditioning Association Journal 1983;5:24-7.

53 Terbizan DJ, Bartels Rl. The effect of set-repetition combinations on strength gain in females age 18-35. Med Sci Sports Exerc $1985 ; 17$ (suppl):S267

54 Vincent K, De Hoyos D, Garzarella L, et al. Relationship between indices of knee extension strength before and after training. Med Sci Sports Exerc 1998;30(suppl): S163

55 Welsch MA, Brechue WF, Pollock ML, et al. Effect of reduced training volume on bilateral isometric knee/extension torque. Med Sci Sports Exerc 1994;26(suppl):S189.

56 Rowles MP, Barnard KL, Adams KJ, et al. Single vs. multiple set strength training in male phase II cardiac patients. Med Sci Sports Exerc 2000;32(suppl):S91.

57 Stone WJ, Coulter SP. Strength/endurance effects from three resistance training protocols with women. J Strength Cond Res 1994;8:231-4.

58 Westcott WL, Greenberger K, Milius D. Strength training research: sets and repetitions. Scholastic Coach 1989;58:98-100.

59 Ostrowski KJ, Wilson GJ, Weatherby R, et al. The effect of weight training volume on hormonal output and muscular size and function. J Strength Cond Res 1997;11:148-54.

60 Stadler LV, Stubbs NB, Vukovich MD. A comparison of a 2-day and 3-day per week resistance training program on strength gains in older adults. Med Sci Sports Exerc 1997;29(suppl):S254.

61 Luecke T, Wendeln H, Campos GR, et al. The effects of three different resistance training programs on cardiorespiratory function. Med Sci Sports Exerc 1998;30(suppl):S198.

62 Chestnut JL, Docherty D. The effects of 4 and 10 repetition maximum weight-training protocols on neuromuscular adaptations in untrained men. J Strength Cond Res 1999;13:353-9

63 Withers RT. Effect of varied weight-training loads on the strength of university freshmen. Res Q 1970;41:110-14.

64 Schmidtbleicher D, Buehrle M. Neuronal adaptation and increase of cross-sectional area studying different strength training methods. In: Jonsson B, ed Biomechanics X-B. Champaign, IL: Human Kinetics, 1987:615-20.

65 Wenzel RR, Perfetto EM. The effect of speed versus non-speed training in power development. Journal of Applied Sports Science Research 1992;6:82-7.

66 Hisaeda H, Miyagawa K, Kuno S, et al. Influence of two different modes of resistance training in female subjects. Ergonomics 1996;39:842-52.
67 Dudley GA, Tesch PA, Miller MA, et al. Importance of eccentric actions in performance adaptations to resistance training. Aviat Space Environ Med 1991;62:543-50.

68 Ciriello VM, Holden WL, Evans WJ. The effects of two isokinetic training regimens on muscle strength and fiber composition. In: Knuttgen $\mathrm{HG}$, Vogel JA, Poortmans J, eds. Biochemistry of exercise. Champaign, IL: Human Kinetics, 1982;13:787-93.

69 Brenner M, Rankin JW, Sebolt D. The effect of creatine supplementation during resistance training in women. J Strength Cond Res 2000;14:207-13.

70 Gravelle BL, Blessing DL. Physiological adaptation in women concurrently training for strength and endurance. J Strength Cond Res 2000;14:5-13.

71 Becque MD, Lochmann JD, Melrose DR. Effects of oral creatine supplementation on muscular strength and body composition. Med Sci Sports Exerc 2000;32:654-8.

72 Fry AC, Webber JM, Weiss LW, et al. Impaired performances with excessive high-intensity free-weight training. J Strength Cond Res 2000;14:54-61.

73 Harris GR, Stone MH, O'Bryant HS, et al. Short term performance effects of high power, high force, or combined weight-training methods. J Strength Cond Res 2000;14:14-20.

74 Mazzetti SA, Kraemer WJ, Volek JS, et al. The influence of direct supervision of resistance training on strength performance. Med $\mathrm{Sci}$ Sports Exerc 2000;32:1175-84.

75 Stone $\mathbf{M H}$, Potteiger JA, Peirce KC, et al. Comparison of the effects of three different weight-training programs on the one repetition maximum squat. J Strength Cond Res 2000;14:332-7.

76 Staron RS, Murray TE, Gilders RM, et al. Influence of resistance training on serum lipid and lipoprotein concentrations in young men and women. J Strength Cond Res 2000;14:37-44.

77 Womack CJ, Flohr JA, Weltman A, et al. The effects of a short-term training program on the slow component of $\mathrm{VO}_{2}$. J Strength Cond Res 2000;14:50-3.

78 Taylor JM, Thompson HS, Clarkson PM, et al. Growth hormone response to an acute bout of resistance exercise in weight-trained and non-weight-trained women. J Strength Cond Res 2000;14:220-7.

79 Bush JA, Dohi K, Mastro AM, et al. Exercise and recovery responses of ymphokines to heavy resistance exercise. J Strength Cond Res 2000; 14:344-9.

80 Bosco C, Colli R, Bonomi R, et al. Monitoring strength training: neuromuscular and hormonal profile. Med Sci Sports Exerc 2000;32:202-8.

81 Kelley GA, Kelley KS. Progressive resistance exercise and resting blood pressure. A meta-analysis of randomized controlled trials. Hypertension 2000;35:838-43.

82 Borst SE, De Hoyos DV, Garzarella L, et al. Effects of resistance training on insulin-like growth factor-l and IGF binding proteins. Med Sci Sports Exerc 2001;33:648-53.

83 Marx JO, Ratamees NA, Nindl BC, et al. Low-volume circuit versus high-volume periodized resistance training in women. Med Sci Sports Exerc $2001 ; 33: 635-43$

84 Kraemer WJ, Ratamess N, Fry AC, et al. Influence of resistance training volume and periodization on physiological and performance adaptation in collegiate women tennis players. Am J Sports Med 2000;28:626-33.

85 Kramer JB, Stone MS, O'Bryant HS, et al. Effect of single vs. multiple sets of weight training: impact of volume, intensity, and variation. $J$ Strength Cond Res 1997;11:143-7. 